\title{
Pandemic times: Learning well in a time of COVID-19
}

\section{DOI: 10.7861/fhj.ed-7-2-2}

When we conceived of the theme of 'learning well' for the June 2020 issue of $F H$ J, it is safe to say that the world was a different place. Our thinking around how to utilise education as a method of promoting improved self-care, wellbeing and belonging within a stretched healthcare system was based on current cultural philosophies of civility, preventing moral injury and burnout, and ensuring that healthcare professionals could be empowered through autonomy and competence - to learn without blame from even the most challenging of situations.

These aims have become even more ambitious, and essential, during the current COVID-19 pandemic. Authors have responded to current circumstances, most explicitly in the opinion piece regarding concepts of risk and sacrifice for healthcare workers from Simons and Vaughan. ${ }^{1}$ We wish our newest colleagues, the interim foundation doctors, the very best for their early start in their medical career, without the joy and excitement of a 'normal' graduation. Equally we hope the welcome that retired clinicians receive as they re-enter clinical practice is as supportive and empathic, and that their wisdom and experience are appreciated.

Three papers in this issue remind us about changes in training and the medical workforce that were not due to the COVID-19 pandemic and have already had a significant impact on physicianly training. Birns and colleagues have summarised their work implementing the internal medical training (IMT) curriculum to make programmes 'IMT ready' and the impact of these changes on trainees. ${ }^{2}$ Hallewell et al describe the implementation of the supported return to training (SuppoRTT) programme, created to support all trainees who have taken a break from clinical work. ${ }^{3}$ This is never more relevant than for those doctors who have been recalled urgently to clinical work from out-of-programme activity and utilising the structures put in place by this initiative delivered by Health Education England across its regions. Finally, a trust-based programme for clinical orientation for international medical graduates resulted in a significant increase in retention and cost improvement - seldom achieved with educational interventions. ${ }^{4}$ Once again, such a programme also addresses the recent need to refresh clinical skills and knowledge in returning physicians, or cross-specialty skills for redeployed doctors, which has been key during the current pandemic response.

While the pandemic has seemingly brought some benefit to our planetary environment, can we capitalise upon this opportunity to rethink our approach to sustainability in healthcare? Gandhi et al argue that healthcare workers have a responsibility for climate health and describe the benefits and challenges of implementing a curriculum in healthcare sustainability. They ask us all to familiarise ourselves with this emerging dimension of learning well. ${ }^{5}$ In a 'playful' way, Guckian, Eveson and May give us an overview of the emerging use of escape rooms in medical education, with varied case studies to illustrate how the concept of gamification is used to challenge learners in simulated environments. ${ }^{6}$ They assert that the concept is grounded in educational theory, but caution that the method may be a fad that passes - although it is likely that humanity's enthusiasm for play will sustain this approach as it further evolves.

The clinical environment is where we learn together. Cheetham et al give us an overview of how the wrong stressors adversely impact on how we learn and retain information. ${ }^{7}$ Incivility is one such extreme stress. This paper helps us understand why we can vividly remember when someone is rude to us but not much else about that moment. Not a healthy environment in which to learn. Learning well can often be pivotal in ensuring that improvement innovations go well. The work by Steel and Bertfield in improving advanced care planning also benefited from consideration of the educational perspective to achieving quality improvement, with a blended approach of teaching and learning. ${ }^{8}$ A similar approach was taken by Earnshaw et al in order to improve the quality of discharge summaries; a task that is pivotal to care across organisational boundaries, yet frequently undervalued within secondary care organisations. ${ }^{9}$ In a second paper, the analysis of activity within a clinical team using personal health records in a simulated urgent and emergency care setting clearly identified the challenges of these systems for the professional care givers and the patients themselves - a key learning opportunity in the paradigm of digital health. ${ }^{10}$ There is also a passionate description of the positive experience of medical students involved in quality improvement projects in primary care, demonstrating that involving learners in service design and change is as important as including staff and patients - they are the future of healthcare delivery. ${ }^{11}$

Finally, the next generation: widening participation is one of the key aims of the 'Dr. Me' project described by Fung, in which over 200 primary school children from areas of relatively high deprivation participated in workshops run by medical students and general practice trainees. ${ }^{12}$ The children were taught about common illnesses and how to manage them appropriately and met young people enthusiastic about their chosen career, likely to impact on their own future career plans.

We are delighted that there is such enthusiasm across the profession for ensuring that we all learn well about health and disease - this energy will continue be needed over the coming months. The future of healthcare professions is, we both hope, bright.

Dr Jo Szram

Consultant respiratory physician, Royal Brompton \& Harefield NHS Foundation Trust

Dr Emma Vaux Senior censor and vice president (education and training), Royal College of Physicians 


\section{Acknowledgements}

We would like to thank Dr Katharine Warburton, our colleague on the editorial board, for her work in support of this issue - it has been very much appreciated. Also, leadership from Dr Kevin Fox has been essential - thanks, as always.

\section{References}

1 Simons J, Vaughan J. Sacrifice and risk in the time of COVID-19. FHJ 2020:7:158-60.

2 Birns J, Mullender C, Balch I, Bryant C, Deaner A. Evaluation of training programmes mapped to the new internal medicine curriculum. FHJ 2020:7:116-9.

3 Hallewell R, Bryant C, Deaner A, Ruggles R, Birns J. Training educational supervisors to support physician trainees returning to practice. FHJ 2020;7:120-4.

4 Quadery SR, Roodbari H, Pardeshi P. Innovative recruitment and clinical orientation programme to manage NHS junior doctor shortfall: A district hospital experience. FHJ 2020;7:131-6.
5 Gandhi V, Al-Hadithy N, Göpfert A et al. Integrating sustainability into postgraduate medical education. FHJ 2020;7:102-4.

6 Guckian J, Eveson L, May H. The great escape? The rise of the escape room in medical education. FHJ 2020;7:112-5.

7 Cheetham LJE, Turner C. Incivility and the clinical learner. FHJ 2020;7:109-11.

8 Steel A, Bertfield D. Increasing advance care planning in the secondary care setting: A quality improvement project. $\mathrm{FHJ}$ 2020;7:137-42.

9 Earnshaw $\mathrm{CH}$, Pedersen A, Evans J. Improving the quality of discharge summaries through a direct feedback system. FHJ 2020;7:149-54.

10 Subbe CP, Pearson N, Wischhusen S et al. Scenario-based design for a hospital setting: An exploratory study of opportunities and barriers for personal health records usage. FHJ 2020;7:125-30.

11 Dolfini L, Williamson G, Oakeshott P. Education: Including medical students in quality improvement projects in primary care. $\mathrm{FHJ}$ 2020;7:155-6.

12 Fung CY. Dr. Me project: Teaching children self-care for self-limiting illnesses in primary schools. FHJ 2020;7:105-8.

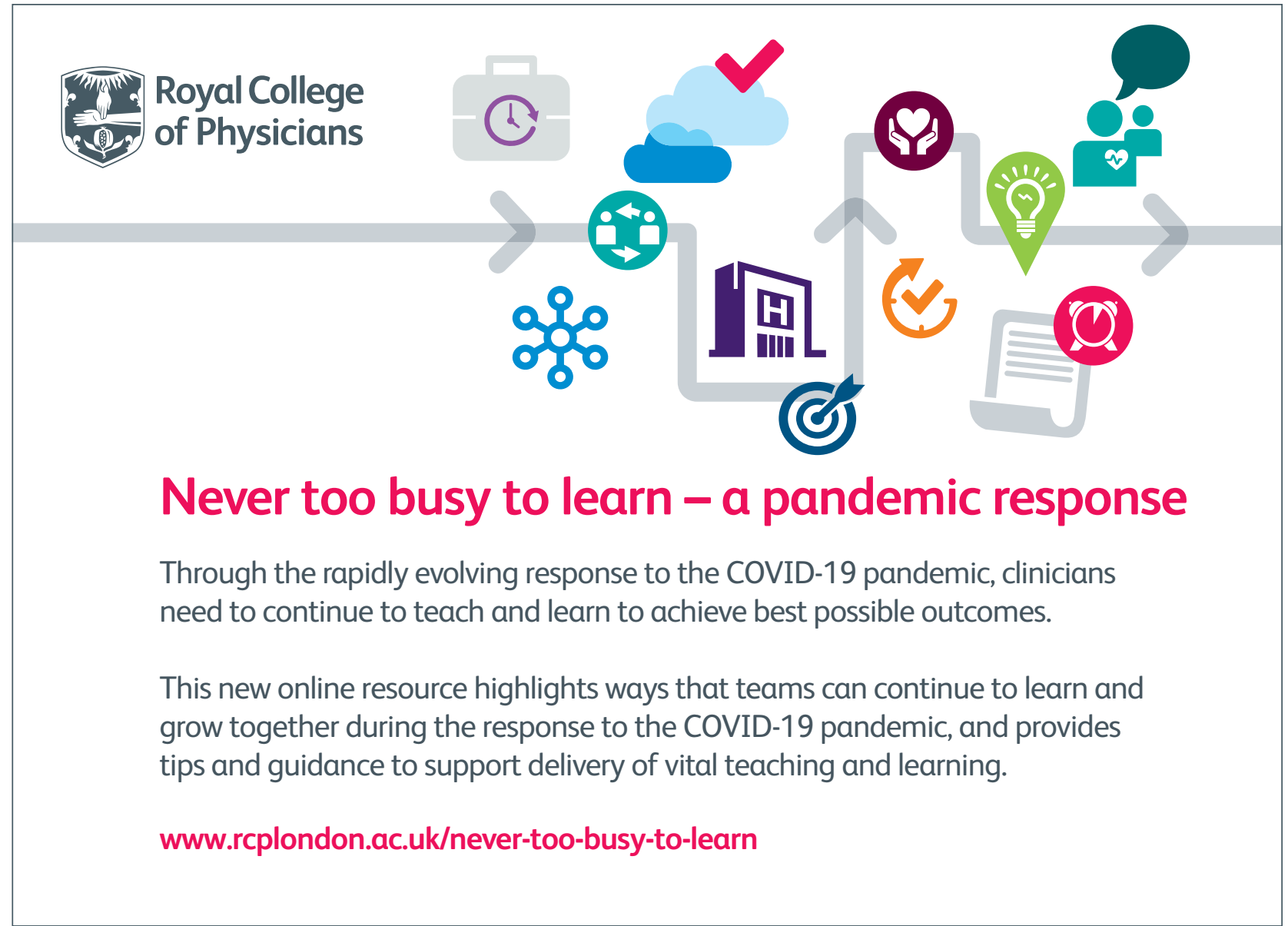

